\title{
HANS JONAS E A FUNDAMENTAÇÃO DE UMA ÉTICA PARA O DESENVOLVIMENTO SUSTENTÁVEL: UMA ANÁLISE DO ART.225 DA CF/88
}

Hans Jonas and the ethical foundation for a sustainable development: an analysis of the art.22 CF/88

\section{Patrícia Lima da Silva}

RESUMO: Este artigo buscou analisar, a partir da já complexa discussão a respeito do desenvolvimento sustentável, como o artigo 225 da Constituição Federal de 1988 pode ser lido sob a luz da ética da responsabilidade de Hans Jonas considerando a já existente e complexa discussão referente ao desenvolvimento sustentável. O filósofo preocupado com o domínio do homem sobre a natureza faz uma critica em relação ao desenfreado avanço tecnológico. $\mathrm{O}$ homem sempre foi capaz de criar, e a cada dia produz mais tecnologias que são lançadas no mercado em um curto espaço de tempo. Apesar dos benefícios, essas ferramentas traz uma serie de impactos sobre a natureza e o homem, sobretudo se não usada de forma sustentável. Preocupado com essas questões o filósofo sugere, portanto, uma ética de responsabilidade para com o futuro, propondo o Princípio Responsabilidade, fazendo o homem repensar suas atitudes em relação ao meio ambiente. O artigo 225 também faz o homem ter responsabilidades sobre o meio, impondo a ele o dever de defender e preservar para as gerações vindouras. Dessa forma, podemos destacar como o princípio moral proposto por Jonas para a superação das crises ambientais e tecnológicas, pode nos servir como suporte filosófico para a leitura do artigo anteriormente citado.

PALAVRAS-CHAVE: Constituição Federal; Tecnologia; Responsabilidade; Hans Jonas.

ABSTRACT: This article seeks to analyze, from the already complex discussion of sustainable development, such as Article 225 of the 1988 Constitution can be read in the light of Hans Jonas responsibility ethics considering the existing and complex discussion regarding sustainable development. The philosopher concerned with man's dominion over nature is a criticism regarding the rampant technological advancement. Man has always been able to create, and every day produces more technologies that are launched in the market in a short time. Despite the benefits these tools bring a series of impacts on nature and man, especially if not used sustainably. Concerned about these issues suggests the philosopher therefore an ethics of

\footnotetext{
${ }^{1}$ Graduada em Tecnologia em Gestão Ambiental pelo Instituto Federal de Educação, Ciência e Tecnologia do Piauí, Campus Corrente. E-mail: patricia.lima.0101@gmail.com. Trabalho desenvolvido sob orientação do Prof. João Batista Farias Junior como requisito para aprovação na disciplina de Ética Ambiental.
} 
responsibility toward the future, proposing the Responsibility Principle, causing the man to rethink their attitudes towards the environment. Article 225 also makes the man have responsibilities for the environment, imposing on it a duty to defend and preserve it for future generations. Thus, we can highlight the moral principle as proposed by Jonas to overcome the environmental and technological crises, can serve us as philosophical support for reading the article cited above.

KEYWORDS: Federal Constitution; Technology; Responsibility; Hans Jonas.

\section{INTRODUÇÃO}

As discussões acerca do desenvolvimento sustentável não são recentes, visto que desde 1972 na Conferência de Estocolmo a Organização das Nações Unidas e seus países membros já discutiam a respeito da relação entre desenvolvimento e meio ambiente. Porém, foi em 1987 que a primeira-ministra norueguesa, Gro Harlem Brundtland, apresentou o conceito de desenvolvimento sustentável, a partir da publicação do Relatório Brundtland - ou Nosso Futuro Comum, elaborado pela Comissão Mundial sobre o Meio Ambiente e Desenvolvimento. De acordo com o mesmo, Desenvolvimento sustentável "é aquele que atende às necessidades do presente sem comprometer a possibilidade de as gerações futuras atenderem as suas próprias necessidades", ou seja, o desafio da humanidade é preservar seu padrão de vida e manter o desenvolvimento tecnológico sem esgotar os recursos naturais do planeta.

No Brasil, esse conceito se tornou tão importante que foi definido na Constituição Federal de 1988, apresentando-se como ponto chave para discussões ambientais. Segundo o art. 225, caput, da CF: "Todos têm direito ao meio ambiente ecologicamente equilibrado, bem de uso comum do povo e essencial à sadia qualidade de vida, impondo-se ao poder público e à coletividade o dever de defendê-lo e preservá-lo para as presentes e futuras gerações". A constituição não utiliza a expressão "desenvolvimento sustentável", no entanto a inserção do dever de defender e preservar o meio ambiente para as presentes e futuras gerações representa a essência do principio da sustentabilidade (MACHADO, 2013, p. 90). Dessa forma tanto o relatório Brundtland quanto o Art. 225 da CF ao abordar o desenvolvimento levando em conta as aspirações futuras, acaba de certa forma sugerindo uma ética de responsabilidade para com o futuro. Nesse contexto, um dos autores que chama a atenção é Hans Jonas.

O filósofo de origem judia nascido em 1903, na cidade de Mönchengladbach na Alemanha, que inicialmente teve sua formação humanística fundamentada na leitura dos profetas hebreus, interessou-se na década de 1970 pelos problemas éticos que poderiam surgir a partir dos 
avanços da tecnologia. Segundo Battestin, (2010) pelo fato de Jonas ter vivenciado a crise europeia nas décadas de 20 e 30, ter presenciado a Primeira Guerra Mundial, os estragos provocados pelas bombas atômicas durante a II Guerra Mundial, o advento do Nazismo, perder sua mãe no campo de concentração, ver o triunfo da sociedade tecnológica, isso de certa forma influenciou no seu pensamento em relação à natureza e o abuso da técnica. Ao presenciar e analisar esses episódios Jonas pode destacar que a ética tradicional já não era mais suficiente para sustentar um debate sobre a ação humana no meio em que estamos vivendo, com isso propôs em 1979 o Princípio Responsabilidade, como sendo um princípio ético, que apresenta diálogo crítico em plena civilização tecnológica.

Segundo Jonas, a natureza não era objeto da responsabilidade humana, pois cuidava de si mesma, e o poder humano não era tão forte. A ética tinha a ver apenas com o aqui e o agora, o futuro era considerado como algo do destino.

[...] O alcance efetivo da ação era pequeno, o intervalo de tempo para previsão, definição de objetivo e imputabilidade era curto, e limitado o controle sobre as circunstâncias. O comportamento correto possuía seus critérios imediatos e sua consecução quase imediata. O longo trajeto das consequências ficava ao critério do acaso, do destino ou da providência. Por conseguinte, a ética tinha a ver com o aqui e agora, como as ocasiões se apresentavam aos homens, com as situações recorrentes e típicas da vida privada e pública. O homem bom era o que se defrontava virtuosa e sabiamente com essas ocasiões, que cultivava em si a capacidade para tal, e que no mais conformava-se com o desconhecido (JONAS, 1994, p. 36-37).

Contudo com o desenvolvimento tecnológico, as atividades que até então eram consideradas de pequeno porte, cresceram de uma forma desenfreada, num curto espaço de tempo, que a natureza não encontrou mais condições de se recuperar por si só, isso porque o homem sempre acreditou que os recursos eram infinitos. "esse foi o ponto de vista prático de todos os tempos, ao longo dos quais o conjunto da natureza parecia invulnerável, estando, portanto, inteiramente disponível para os homens, como objeto de usos particulares" (JONAS, 2006, p. 230).

O que se pode perceber é que o emprego histórico dessas tecnologias acarretou num grande êxito econômico, esse conduziu para o conforto e bem estar populacional, porém trouxe uma grande problemática: a superpopulação. $\mathrm{O} \int 1^{\circ}, \mathrm{V}$, do art. 225 , aponta que incube ao poder público "controlar a produção, a comercialização e o emprego de técnicas, métodos e substâncias que comportem risco para a vida, a qualidade de vida e o meio ambiente". No entanto com o crescimento exponencial da população, a produção, comercialização tornou-se desenfreada, necessitando de mais tecnologias para satisfazer a necessidade de consumo, submetendo o meio 
ambiente a uma agressão que está provocando o declínio cada vez mais acelerado de sua qualidade e de sua capacidade para sustentar a vida. "A explosão demográfica, compreendida como problema metabólico do planeta, rouba as rédeas da busca de uma melhora no nível de vida" (JONAS, 2006, p. 236).

Hoje quando vemos o ser humano e o planeta perigosamente ameaçados, a reflexão de Hans Jonas é extremamente pertinente e iluminadora (SOUZA, 2010). O principal problema desde então foi isolar o ser humano do restante da natureza, uma vez que o homem é a própria natureza. Sendo assim ele deve incluir o dever de protegê-la, como condição de sua própria existência.

O art. 225 da constituição já aponta esse dever, quando enfoca a restauração, recuperação e reparação do meio ambiente, em seu $\int 1^{\circ}$, I, destaca a obrigação de "preservar e restaurar os processos ecológicos essenciais e prover o manejo ecológico das espécies e ecossistemas". No $\int 2^{\circ}$ "aquele que explorar os recursos minerais fica obrigado a recuperar o meio ambiente degradado, de acordo com solução técnica exigida pelo órgão público competente, na forma da lei". E no $\int 3^{\circ}$ consta o principio da responsabilidade. Segundo o qual, os responsáveis pela degradação ao meio ambiente são obrigados a arcar com a responsabilidade e com os custos da reparação ou da compensação pelo dano causado. "As condutas e atividades consideradas lesivas ao meio ambiente sujeitarão aos infratores, pessoas físicas ou jurídicas, a sanções penais e administrativas, independentemente da obrigação de reparar os danos causados".

Hans Jonas também defende no seu capítulo IV a responsabilidade pelos danos causados:

O agente deve responder por seus atos: ele é responsável por suas consequências e responderá por elas, se for o caso. Em primeira instância, isso deve ser compreendido do ponto de vista legal, não moral. Os danos causados devem ser reparados, ainda que a causa não tenha sido um ato mau e suas consequências não tenham sido nem previstas nem desejadas. Basta que eu tenha sido a causa ativa. (JONAS, 2006, p.165).

O filósofo apesar de defender que todos devem responder por seus atos aponta que nem sempre o dano é um ato mau, muitas vezes pode ocorrer por descuido, "o ato é castigador quando se trata de um crime, e é em virtude dele que sua pena é calculada, levando em conta a decisão, a premeditação, o motivo e a imputabilidade" (JONAS, 2006, p.165). Também é possível notar no art. $225, \int 3^{\circ}$, da $\mathrm{CF}$, anteriormente citado que há uma diferenciação daquilo que é malicioso para um ato de negligência. É nesse sentido que aparece as três modalidades de responsabilidade ambiental: Penal, Civil e administrativa. Segundo Machado, (2013) a reparação do meio ambiente quanto à natureza civil independe de culpa do autor da ação ou omissão, já a 
sanção penal ou administrativa requer a demonstração de culpa. Como podemos perceber Jonas pode nos servir como suporte filosófico para a leitura do artigo anteriormente citado, sua visão nos leva a uma reflexão sobre o atual modelo de desenvolvimento.

Cabe destacar que apesar de criticar os avanços tecnológicos, Jonas não ajuizava retroceder ao passado, ele reconhecia os benefícios advindos da tecnologia, como pode ser observado no título do item IV, “a tecnologia é uma vocação da humanidade”, pois, graças a ela, o homem foi sempre capaz de suprir suas necessidades. Santos destaca que:

Jonas não seria ingênuo ou tolo para fazer uma mera apologia de um retorno dos homens às cavernas e florestas. Não se trata de uma atitude simplesmente contra o progresso, contra a pesquisa e o desenvolvimento científico. O que o pensador judeu-alemão sinaliza é que os riscos devem ser calculados, e adverte que se deve assumir no cálculo a própria impossibilidade de se prever todas as consequências (SANTOS, 2012, p. 424-425).

Segundo Fonseca, (2009) do ponto de vista das tecnologias em geral, as conquistas são inumeráveis. Podendo destacar como exemplo a eletricidade, onde foi possível integrar ao cotidiano uma série de utensílios para facilitar e aumentar o conforto. Por outro lado o consumo desregrado desses bens materiais acaba contribuindo para as mudanças climáticas, escassez dos recursos, entre outros. O computador, celular, por exemplo, são trocados constantemente por um novo modelo lançado no mercado, e o homem em busca de lucros deixa de valorizar a durabilidade do produto, se atentando apenas para consumismo, gerando assim, grande quantidade de lixo que acaba por diminui a vida útil dos aterros, amplia a extração de matéria prima, gastos com energia, água, emissão de poluentes gerados durante a produção de um novo produto.

Quando o art. 225 da CF expressa desenvolvimento sustentável, também não visa barrar o progresso e sim conciliar o desenvolvimento levando em conta os fatores: econômico, social e ambiental, a fim de garantir os recursos para as gerações vindouras. O inciso II aponta que as entidades dedicadas à pesquisa e manipulação de material genético devem ser fiscalizadas, dessa forma não condena tal prática. O inciso III define que alteração e a supressão são permitidas desde que feita na forma da lei, e o inciso IV destaca que para instalação de obra ou atividade potencialmente causadora de significativa degradação do meio ambiente, será exigido o estudo prévio de impacto ambiental. No $\int 6^{\circ}$ também destaca que as usinas que operem com reator nuclear deverão ter sua localização definida em lei federal, sem o que não poderão ser instaladas. Note que nos incisos: II III e IV do $\int 1^{\circ}$ e no $\int 6^{\circ}$ do art. 225 em nenhum momento faz apologia a fim de barrar o crescimento e desenvolvimento do país, pelo contrário, as atividades poderão ser desenvolvidas desde que estejam em acordo com o que determina a lei. 
O estudo prévio conforme citado no inciso IV, é a garantia de viver num ambiente ecologicamente equilibrado, pois qualquer atividade ou instalação que apresenta potencial de poluição ou degradação ambiental deve apresenta-lo a fim de identificar os possíveis impactos, confrontando com a hipótese de não execução da atividade, ou execução tendo em conta as medidas mitigadoras. Porém mesmo estando definido na Constituição Federal, geralmente não é bem o que acontece. Machado aponta que:

O Estudo Prévio de Impacto Ambiental está inserido na Constituição Federal. Mas, na prática, o texto constitucional vai sendo, dia-a-dia, solapado pela introdução de procedimentos preliminares que não tem sido rapidamente invalidados judicialmente. Com os astutos golpes deferidos, a prevenção dos danos ambientais no Brasil vai ficando gradativamente ineficaz, até aniquilar-se. (MACHADO, 2013, p. 315).

Esse se torna um grande problema porque de acordo com Jonas, (2006) no tempo de que ainda dispomos, as correções tornam-se cada vez mais difíceis, essas circunstâncias reforçam a obrigação de vigiar os primeiros passos, ou seja, se já está difícil recuperar o que ao longo dos tempos se desgastou, fica mais difícil se o que foi definido na lei não estiver sendo cumprido, porque a lei é pra nortear nossos passos. Dessa forma é essencial sensibilizar as pessoas. O art. $225 \int 1^{\circ}, \mathrm{VI}$, aponta que deve se promover a educação ambiental em todos os níveis de ensino, bem como a conscientização pública para a preservação do meio ambiente. Portanto a educação ambiental deve ser implantada em busca de uma nova ética que permeie os nossos comportamentos e a nossa relação com o ambiente.

\section{CONSIDERAÇÕES FINAIS}

Considerando à reflexão de Hans Jonas, frente ao artigo 225 da Constituição Federal, pode se estabelecer que o meio ambiente é um direito de todos, mas não pertence a ninguém individualmente, ou seja, é um bem difuso (indivisível). Nesse contexto cabe a cada um protegêlo para garantir a permanecia das espécies, bem como o equilíbrio ecológico, assim o Princípio Responsabilidade se apresenta aqui como a primeira condição ética e responsável para com as gerações.

Na visão de Jonas, só haverá equilíbrio se o homem começar a se sentir responsável, pois enquanto estiver vendo a natureza de forma unicamente capitalista, os estragos vão crescendo, e tomando diferente dimensão. O grande problema a ser levado em conta não é o desenvolvimento, mas a velocidade com que ele vem acontecendo. A terra sempre criou mecanismos de adaptação, no entanto, isso demanda certo tempo, não é feito de uma hora pra 
outra. E as ações humanas vêm ocorrendo de uma forma bastante acelerada e a terra não tem conseguido acompanhar esse ritmo. O principal objetivo, portanto, passa a ser o de sensibilizar as pessoas, para que essas hajam de forma responsável, o que vem sendo feita sobre diversas formas, a exemplo das disciplinas de educação ambiental, a mídia, a própria comunidade, ao adotar uma postura de compromisso, e esse compromisso só é alcançado se cada elo se sentir como parte do meio.

Uma vez informados sobre os efeitos de suas ações ao meio ambiente, espera-se que a população sinta-se motivada a utilizar os recursos naturais de forma sustentável, se tornando cidadãos conscientes a respeito do seu papel na sociedade. Assim, é extremamente pertinente considerar a reflexão de Jonas, pois o filósofo trata de forma precisa, sobre a importância de uma responsabilidade que contemple as gerações vindouras, o que está elencado na própria Constituição Brasileira, a Carta Magna. 


\section{REFERÊNCIAS}

JONAS, Hans. O Princípio responsabilidade: ensaio de uma ética para a civilização

tecnológica. Rio de Janeiro: Contraponto/Editora PUC-Rio, 2006.

Ética, medicina e técnica. Lisboa: Vega Passagens, 1994.

BATTESTIN, Cláudia; GHIGGI, Gomercindo. O Princípio Responsabilidade de Hans

Jonas: um princípio ético para os novos tempos. Thaumazein, Ano III, número 06, Santa Maria. Out. 2010, p. 69-85.

BRASIL. Constituição Federal de 1988. Brasília: Senado Federal, 1988.

FONSECA, Lilian Simone Godoy. Hans Jonas e a responsabilidade do homem frente ao desafio biotecnológico. Tese (Doutorado em Filosofia) - Faculdade de Filosofia e Ciências Humanas, Universidade Federal de Minas Gerais, Belo Horizonte, 2009.

MACHADO, Paulo Affonso Leme. Direito Ambiental Brasileiro. 21 ed. São Paulo: Malheiros Editores, 2013.

SANTOS, Robinson dos. Responsabilidade e consequencialismo na ética de Hans Jonas.

Revista de filosofia aurora, Curitiba, v. 24, n. 35, p. 417-433, jul./dez. 2012.

SOUZA, Waldir. "O Princípio responsabilidade" em Hans Jonas: um desafio para a bioética numa contínua transcendência. Revista do Dpto. de Teologia da PUC-Rio / Brasil. Ano XIV no 35, maio/ago. 2010. 